\title{
Isostatic stability of the East Antarctic station Dumont d'Urville from long-term geodetic observations and geophysical models
}

\author{
Martine Amalvict, ${ }^{1}$ Pascal Willis, ${ }^{2,3}$ Guy Wöppelmann, ${ }^{4}$ Erik R. Ivins, ${ }^{5}$ Marie-Noëlle Bouin, ${ }^{6}$ Laurent Testut ${ }^{7}$ \& \\ Jacques Hinderer ${ }^{1}$ \\ 1 Institut de Physique du Globe de Strasbourg (UMR 7516 CNRS-ULP), 5 Rue René Descartes, 67000 Strasbourg, France \\ 2 Institut Géographique National, Direction Technique, 2 Avenue Pasteur, BP 68, 94160 Saint-Mandé, France \\ 3 Institut de Physique du Globe de Paris, Géophysique Spatiale et Planétaire, 35 rue Hélène Brion, 75013 Paris, France \\ 4 Centre Littoral de Géophysique, Université de La Rochelle, Avenue Michel Crépeau, 17042 La Rochelle Cedex 1, France \\ 5 Jet Propulsion Laboratory, California Institute of Technology, Pasadena, CA 91109, USA \\ 6 Institut Géographique National, LAREG, 6 et 8 Avenue Blaise Pascal, 77455 Marne-la-Vallée Cedex, France \\ 7 LEGOS-UMR5566-CNRS/CNES/UPS/IRD-14 Avenue Edouard Belin, 31400 Toulouse, France
}

\section{Keywords}

Absolute gravity; Antarctica; DORIS; Dumont

d'Urville; GPS; tide gauge.

\section{Correspondence}

Pascal Willis, Institut de Physique du Globe de Paris, Géophysique Spatiale et Planétaire, 35 rue Hélène Brion, 75013 Paris, France.

E-mail:willis@ipgp.jussieu.fr

doi:10.1111/j.1751-8369.2008.00091.x

\begin{abstract}
Geodetic measurements of the vertical crustal displacement collocated with absolute gravity changes provide a discriminatory measurement of present-day glacial changes, versus more deeply seated rock motions caused by glacial isostatic adjustment (GIA). At the East Antarctic station of Dumont d'Urville, we compare the displacements derived from continuous DORIS (1993.02006.0) and Global Positioning System (GPS) (1999.0-2005.7) data, and observed changes in absolute gravity (2000-2006), with the predicted vertical displacement and change in gravity from GIA modelling. The geodetic results have mutual self-consistency, suggest station stability and provide upper bounds on both GIA and secular ice mass changes. The GIA models tend to predict amplitudes of rock motion larger than those observed, and we conclude that this part of Antarctica is probably experiencing a slight gain in ice mass, in contrast to West Antarctica.
\end{abstract}

The mass change of the Antarctic ice sheet plays a key role in mean sea-level variation (Nerem et al. 2006), but estimates of Antarctic mass balance are still controversial (e.g., Rignot \& Thomas 2002). The ice mass budget results from the combination of accumulation (precipitation) and ablation (calving, ice shelf collapse and basal melting). Recent studies (Chen et al. 2006; Ramilien et al. 2006; Velicogna \& Wahr 2006; Rignot et al. 2008) suggest the possibility of a recent (2002-06) acceleration of Antarctic mass loss. However, such a loss is primarily in the West Antarctic Ice Sheet. GRACE results especially suggest that mass of the East Antarctic Ice Sheet (EAIS) is either close to equilibrium (Velicogna \& Wahr 2006) or slightly increasing (Ramilien et al. 2006). A mass increase is also seen in radar altimetry (Davis et al. 2005; Zwally et al. 2005), and mass balance considerations mainly based on remote sensing (Rignot \& Thomas 2002; Remy $\delta$ Frezzotti 2006) suggest that EAIS is close to equilibrium. Similar to the vertical motion of the crust, the ice surface height variation may also be associated with either glacial isostatic adjustment (GIA) or present-day ice mass (PDIM) variability. Wahr et al. (1995) noted that a comparison of observations using absolute gravity (AG) and satellite geodetic techniques offers one method of separating the two different signals. Antarctic AG measurements began in 1990, and have been taken on a regular basis since then (e.g., Mäkinen et al. 2007). Although AG measurements are available at 12 stations, repeated observations are only available at five stations: Terra Nova Bay, McMurdo, Syowa, Abao and Dumont d'Urville, all located in the eastern part of the Antarctic continent. Like most of the AG stations, Dumont d'Urville (DdU) has long been collocated with satellite geodesy measurements (GPS and DORIS) (Fig. 1). Using these collocated observations, we aim to assess whether this area of East Antarctica is stable, and to determine which part of the vertical motion observed is related to GIA or PDIM changes. We focus on this station for two main reasons: (1) this is the only opportunity in this part of Antarctica to conjointly use AG measurements and 
(a) Pointe Géologie - Cap Prud'homme

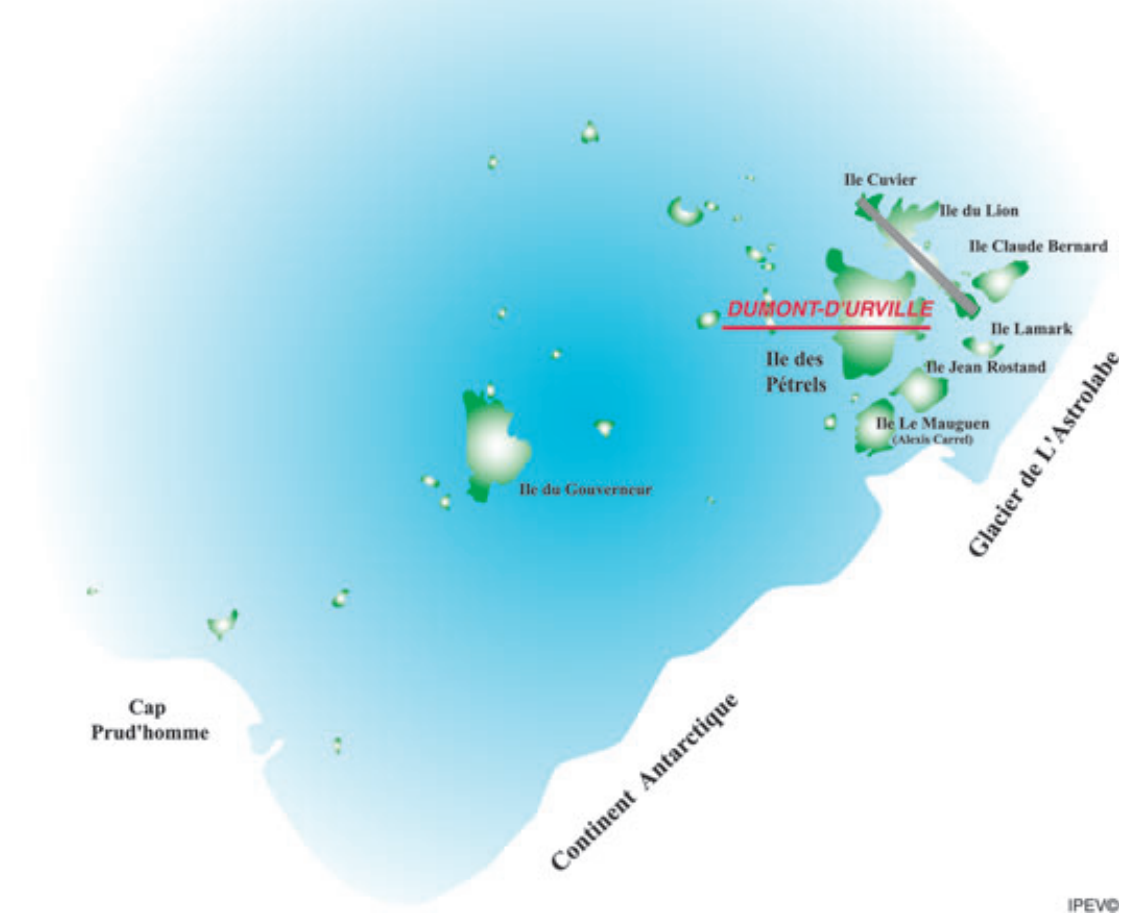

(b)

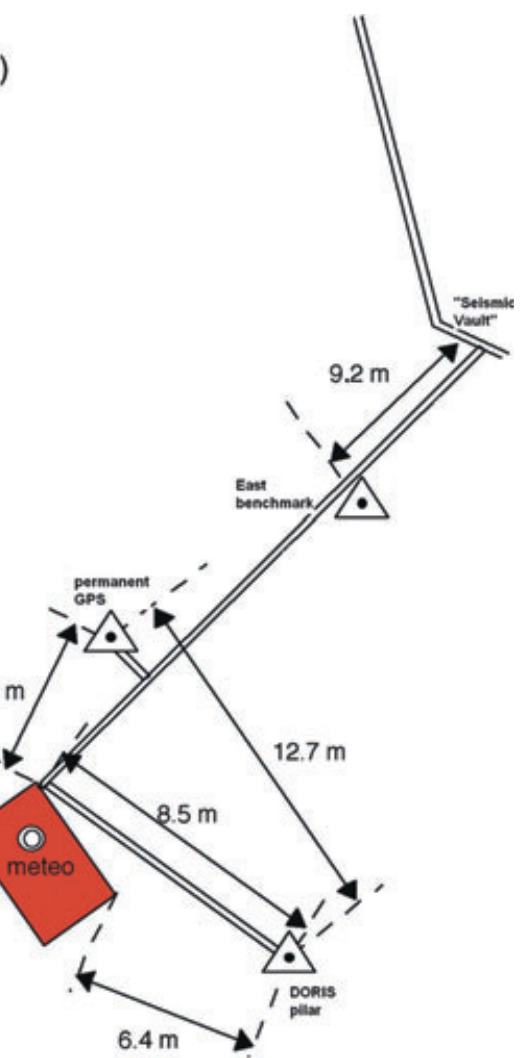

Fig. 1 (a) The geographical location of Dumont d'Urville station in Antarctica (reproduced with permission of the French Polar Institute), and (b) the location of geodetic instruments, based on information from the Institut Géographique National/Service d'Installation et de Maintenance des Balises (see Fagard 2006). 
multi-technique space geodesy positioning, and (2) as this part of East Antarctica is supposed to be stable, DdU behaviour should be representative of the surrounding area. In restricting our focus on DdU, we do not aim to constrain the Antarctic intraplate stability, nor the horizontal glacial deformation.

The DdU station $\left(66.67^{\circ} \mathrm{S}, 140.17^{\circ} \mathrm{E}\right)$ was established in 1950 on Petrel Island in the Terre Adélie sector, East Antarctica (Fig. la). Since that time geodetic operations have been regularly carried out during the yearly occupation of the station, or during summer campaigns (in 1995 and 1996). Twenty years ago, a new era began with the introduction of satellite geodesy and Global Navigation Satellite Systems (GNSS) precise positioning (Figs. 1b, 2). Figure $1 \mathrm{~b}$ shows the location of the different geodetic instruments, while Fig. 2 presents the data availability per technique.

In this paper, we first present results from geodetic observations at DdU: DORIS since 1993, GPS since 1997, and surface AG observations from 2000 and 2006. We validate our 3D DORIS and GPS velocities by comparing them with recent geodetic or geophysical plate motion models, and then investigate the GIA and present-day effects using both measurements and IJ05 GIA model predictions (Ivins \& James 2005).

\section{GPS data}

Early GPS observations were performed at DdU in 1995 , from January 30 to February 8, and in 1996, from January 20 to February 10, by the Institut Géographique National (IGN), within the Scientific Committee on Antarctic Research (SCAR) campaigns. A permanent GPS station was installed at DdU in December 1997 (Bouin \& Vigny 2000). This GPS site (DUMl) is now part of the International GNSS Service (IGS) network (Dow et al.

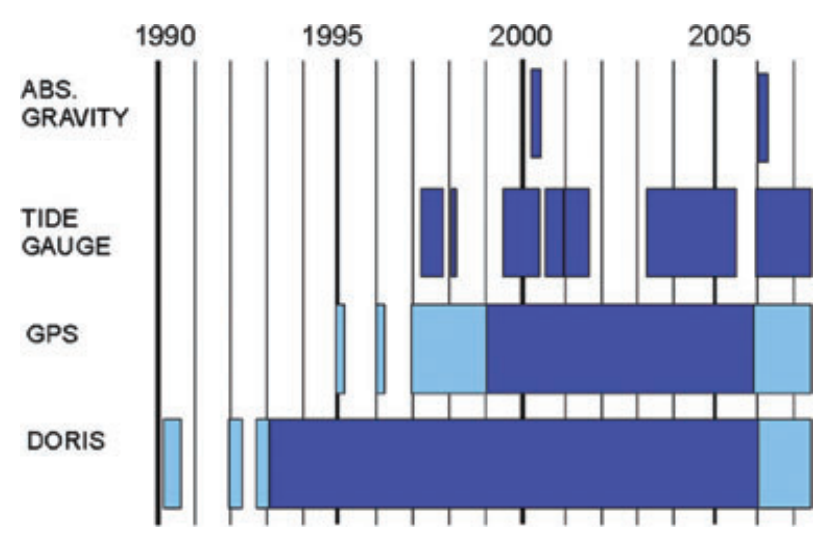

Fig. 2 Geodetic data available at Dumont d'Urville station. The data used in this study are in the darker shade.
2005), and fortunately the antenna was set up on the same pillar as that used during the campaign measurements. DUMl has been continuously operating for 10 years, and contributes to the IGS pilot project TIGA that aims to monitor the stability of the land upon which the tide gauges are settled (Wöppelmann et al. 2007; Wöppelmann et al. 2008).

A dedicated analysis centre was set up at the University of La Rochelle, which analyses the GPS data from DUM1, along with 223 other stations, on a routine basis. This GPS processing is performed using GAMIT software (King $\delta$ Bock 2005) on a free network approach and with a stateof-the-art strategy, which is described extensively by Wöppelmann et al. (2007) and Wöppelmann et al. (2008). Absolute receiver phase centre corrections, satellite antennae modelling and the Global Mapping Function (GMF) Troposphere mapping function from Boehm, Niell et al. (2006) are used in the processing scheme. Vienna mapping functions 1 (VMFl; Boehm, Werl et al. 2006) are known to more accurately model tropospheric seasonal variations, especially in Antarctica. Nevertheless, the VMF grids were not available at the time this processing began, and were therefore not used in this work. A particular concern in the GPS data processing was to ensure the most rigorous possible consistency in the models and corrections that were applied over the whole data span. No atmospheric loading modelling was used, as the current model (Tregoning \& van Dam 2005) is too imprecise to include subdiurnal effects (Ray, pers. comm.). The weekly GPS solutions are combined using CATREF software, and are aligned to ITRF2000 using the minimal constraints approach described by Altamimi et al. (2002). The reprocessing of DdU observations has been performed backwards for GPS data spanning the period 1999.02005.7 (a time span of 6.7 years). Possible seasonal effects caused by atmospheric loading or unmodelled tropospheric variations do not influence our velocities, as this observation period greatly exceeds the minimum limits set by Blewitt \& Lavallée (2002). Results for DUMl are presented in Table 1 and Fig. 3.

The observed linear trends for horizontal north and east components are, respectively: $-11.11 \pm$ $0.08 \mathrm{~mm} \mathrm{yr}^{-1}$ and $7.98 \pm 0.07 \mathrm{~mm} \mathrm{yr}^{-1}$. These GPSderived velocities are consistent with the previous results obtained using GPS $\left(-13 \pm 3 \mathrm{~mm} \mathrm{yr}^{-1}\right.$ and $15 \pm 10 \mathrm{~mm} \mathrm{yr}^{-1}$; Bouin \& Vigny 2000) or a multitechnique combination $\left(-8.1 \pm 1.0 \mathrm{~mm} \mathrm{yr}^{-1}\right.$ and $11.6 \pm$ $0.8 \mathrm{~mm} \mathrm{yr}^{-1}$; Altamimi et al., 2002). Our vertical rate is $0.34 \pm 0.12 \mathrm{~mm} \mathrm{yr}^{-1}$. In a previous study, Mäkinen et al. (2007) provided two different values without giving any formal errors for the vertical trends $\left(-0.56 \mathrm{~mm} \mathrm{yr}^{-1}\right.$ and $+0.43 \mathrm{~mm} \mathrm{yr}^{-1}$ ). Here, we claim that our results, which are consistent with the second value, are more accurate 
Table 1 Observations and modelling of changes in gravity, and in horizontal and vertical displacements, at Dumont d'Urville station, East Antarctica.

\begin{tabular}{|c|c|c|c|c|c|}
\hline & $A G^{a}$ & DORISa & $\mathrm{GPS}^{a}$ & GIA model ${ }^{a}$ & Plate motion ${ }^{b}$ \\
\hline $\mathrm{d} u / \mathrm{d} t \mathrm{~mm} \mathrm{yr}^{-1}$ & - & $0.29 \pm 0.13$ & $0.34 \pm 0.12$ & 2.49 & 0 \\
\hline North component $\mathrm{mm} \mathrm{yr}^{-1}$ & - & $-10.09 \pm 0.16$ & $-11.11 \pm 0.08$ & - & $-13<<-11$ \\
\hline East component $\mathrm{mm} \mathrm{yr}^{-1}$ & - & $10.85 \pm 0.21$ & $7.98 \pm 0.07$ & - & $7<<9$ \\
\hline $\mathrm{d}(\delta g) / \mathrm{d} t \mu \mathrm{Gal} y r^{-1}$ & $-0.22 \pm 0.38$ & - & - & -0.37 & - \\
\hline
\end{tabular}

aThis study.

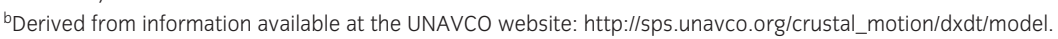
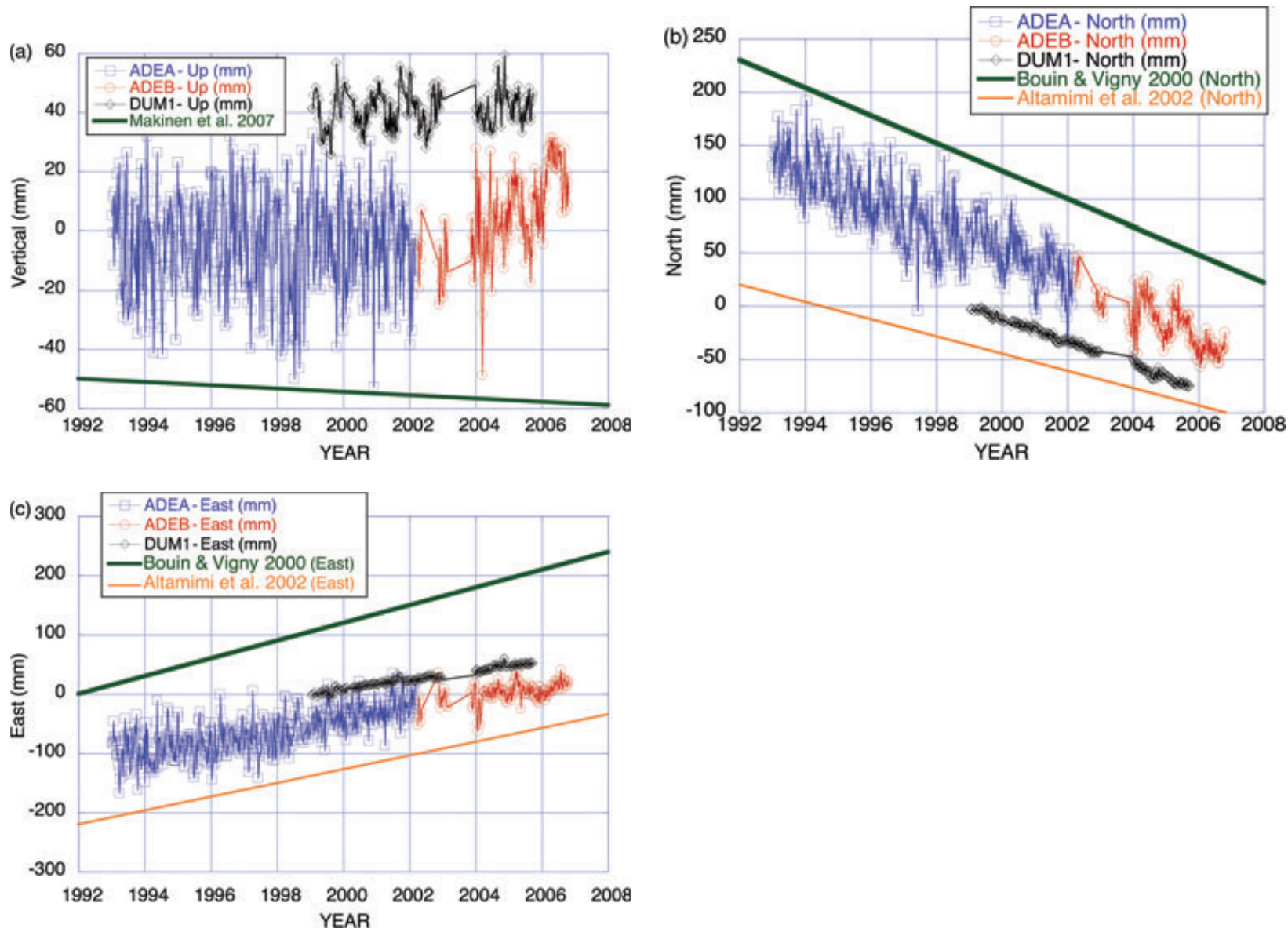

Fig. 3 DORIS (ADEA and ADEB) and GPS (DUM-1) position residual time series in mm: (a) vertical, (b) north horizontal and (c) east horizontal components.

than the earlier determinations for two main reasons: (1) we used a state-of-the-art processing strategy, including new models and a validated reference frame realization, and (2) our GPS processing strategy is consistent throughout the whole time series, which was not the case in the previous studies. For the same reason, our time series behaviour has been shown to be extremely close to a pure white-noise process (Feissel-Vernier et al. 2007), without any flicker noise. This makes us quite confident of the uncertainties associated with our results. The consistency with previous results (Bouin \& Vigny 2000; Altamimi et al. 2002) simply demonstrates the robustness of our results.

\section{DORIS data}

The DORIS (Doppler Orbitography and Radiopositioning Integrated by Satellite) station in Terre Adélie has been almost continuously observing since the introduction of the system. The DORIS station in Terre Adélie (Tavernier et al. 2006) was installed on 5 February 1987 (ADEA, Alcatel antenna), and was later upgraded on 1 March 2002 (ADEB, Starec antenna). The 1993.0-2006.0 data were processed on a daily basis using the GIPSY/OASIS II software and a free-network approach, and were then combined at the normal matrix level into weekly freenetwork solutions (Willis et al. 2005). A cumulative 
solution (position/velocity) was derived using information on station discontinuity from Willis \& Ries 2005). This solution was then projected and transformed (using a 14-conformal transformation) into ITRF2000 and ITRF2005P (Altamimi et al. 2007).

As a result of the nearly polar orbit of the SPOT satellites, the high-latitude DORIS stations provide a richer source of data, from which we achieve results of higher accuracy. On the other hand, the station vertical component, highly correlated with the $z$-axis, is potentially affected by systematic errors (Willis et al. 2006). It must be noted that the results from DORIS are usually as accurate in the horizontal component as in the vertical component. In particular, in order to avoid correlation between the DORIS vertical results and the tropospheric correction, a specific time constraint is used in the GIPSY/ OASIS II estimation between consecutive passes of any satellites (see Snajdrova et al. [2006] for a description of the technique, as well as for comparisons of the tropospheric delay with Very Long Baseline Interferometry [VLBI], GPS and water vapour radiometry [WVR] results).

DORIS results are given in Table 1 and Fig. 3. The observed linear trends for vertical, and horizontal north and east components are, respectively, $0.29 \pm$ $0.13 \mathrm{~mm} \mathrm{yr}^{-1}, \quad-10.09 \pm 0.16 \mathrm{~mm} \mathrm{yr}^{-1}$ and $10.85 \pm$ $0.21 \mathrm{~mm} \mathrm{yr}^{-1}$. The precision provided in these results is the formal error after reweighting using the $\chi^{2} / \mathrm{DOF}$ value of the combination (adding the DORIS weekly matrices over the full period). In our opinion, these precisions are more realistic that the initial formal errors (without any $\chi^{2}$ reweighting), and are typically smaller by a factor of 2 .

\section{AG data}

In the framework of a project supported by the French Polar Institute (IPEV), and dedicated to AG measurements in sub-Antarctic and Antarctic French scientific stations, AG was measured twice at DdU. Absolute gravimeter FG5-206, of the Strasbourg Gravimetric Observatory, was set up in a shelter established on the bedrock, and measurements were obtained from 26 February to 2 March 2000, and on 5-8 February 2006. The 2000 experiment (11 800 drops in $118 \mathrm{~h}$ ) is described in Amalvict et al. (2001) and Hinderer et al. (2002). The 2006 experiment (16 187 drops in $82 \mathrm{~h}$ of continuous measurement) is described in Amalvict et al. (2007). We processed the raw data using Micro-g Solutions "g" v6.06 software, and reduced the observations in a similar way for the two campaigns, using the same vertical gradient of gravity, and the same models for the solid Earth tides, ocean tides, motion of the pole of rotation (using the published $x$ and $y$ components from the International Earth Rotation and
Reference Systems Service [IERS] Bulletin B) and atmospheric pressure effects using the standard nominal pressure (see Mäkinen et al. 2007). The respective values of gravity are $g_{2000}=982387168.34 \pm 1.68 \mu \mathrm{Gal}$ and $g_{2006}=982387167.02 \pm 1.54 \mu \mathrm{Gal} \quad\left(1 \mu \mathrm{Gal}=10^{-8} \mathrm{~ms}^{-2}\right)$. The corresponding gravity variation over 6 years (2000-2006) is $-0.2 \pm 0.4 \mu \mathrm{Gal} \mathrm{yr}^{-1}$ (Table 1), i.e., a nonsignificant small decrease in gravity. The error on this trend takes into account the 2000 and 2006 experimental standard deviations of the mean $(\sigma / N$, where $\sigma$ is the set scatter and $N$ is the total number of sets), the set-up noise $(1 \mu \mathrm{Gal})$, and the system (instrument type) noise $(1.1 \mu \mathrm{Gal})$, these last two quantities being defined for FG5 by Micro-g Solutions.

\section{Modelling}

The IJ2005 (Ivins \& James 2005) model (uplift shown in Fig. $4 \mathrm{a} ; 2.49 \mathrm{~mm} \mathrm{yr}^{-1}$ in DdU) assumes a simple threelayer mantle structure, tailored to the optimum global viscosity model (MF) of Mitrovica \& Forte (2004).

The glacial history assumes continuous drawdown of ice heights since 3.2 Kya and that all change has ceased at the time of evaluation, so that the uplift is computed purely on the basis of past glacial changes. The model is radially stratified, self-gravitating, and only the ocean load associated with Antarctic glaciation and deglaciation is included. The effects of accounting for the total ocean loading are not negligible, but are quite small in comparison with direct loading effects, such as the last $2 \mathrm{Ky}$ of glacial history, as discussed by Ivins \& James (2005). The model includes enhanced precipitation on the East Antarctic coast after the Antarctic Cold Reversal, and during Holocene times. This is clearly found in the analyses of ice core record data (Wolff et al. 2006), and is supported by global circulation model simulations of the Last Glacial Maximum climate (Toracinta et al. 2004). We minimally account for an early Holocene glacial expansion into Prydz Bay (Domack et al. 1991); however, we lack information on the ice extent and mass involved. Figure $4 \mathrm{~b}$ shows the predicted present-day secular rate of change for surface gravity $\left(-0.37 \mu \mathrm{Gal} \mathrm{yr}^{-1}\right.$ in DDU). The ice model in this region of Antarctica is quite uncertain. No ab initio effort was made to adjust the load, nor the mantle viscosity parameters, as the main point here is to demonstrate that these geodetic observations hold promise for providing significant tests of such model predictions.

\section{Results and discussion}

Our horizontal and vertical velocities obtained from DORIS and GPS data are in mutual agreement (see Fig. 3 


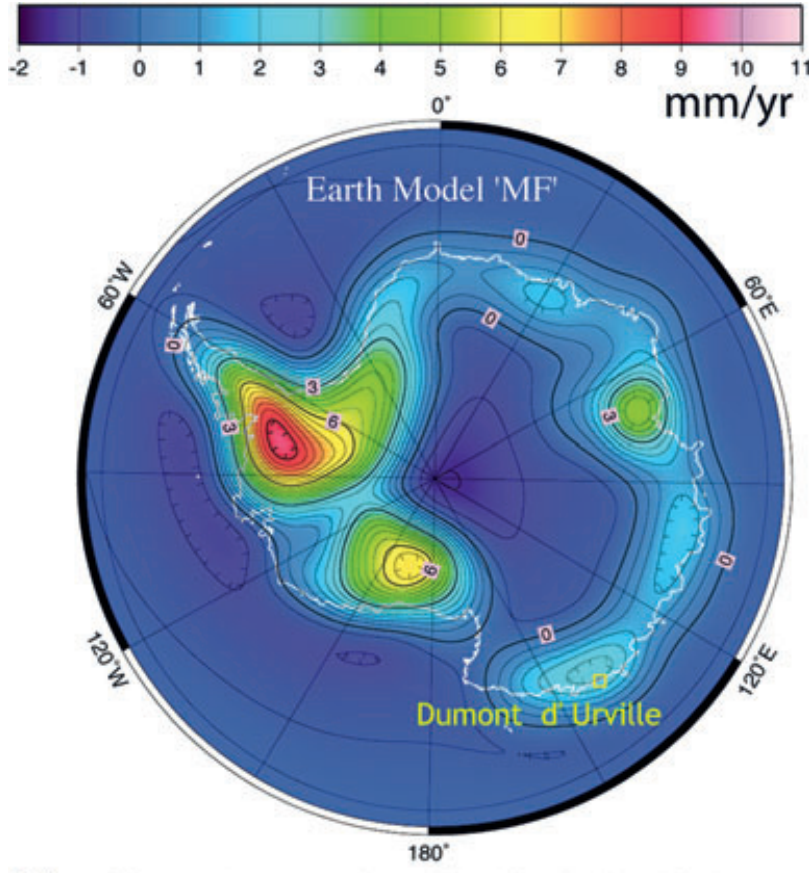

(a) uplift rate in $\mathrm{mm} / \mathrm{yr}$ for $1 \mathrm{J05}$ with $10.13 \mathrm{~m}$ ESLR

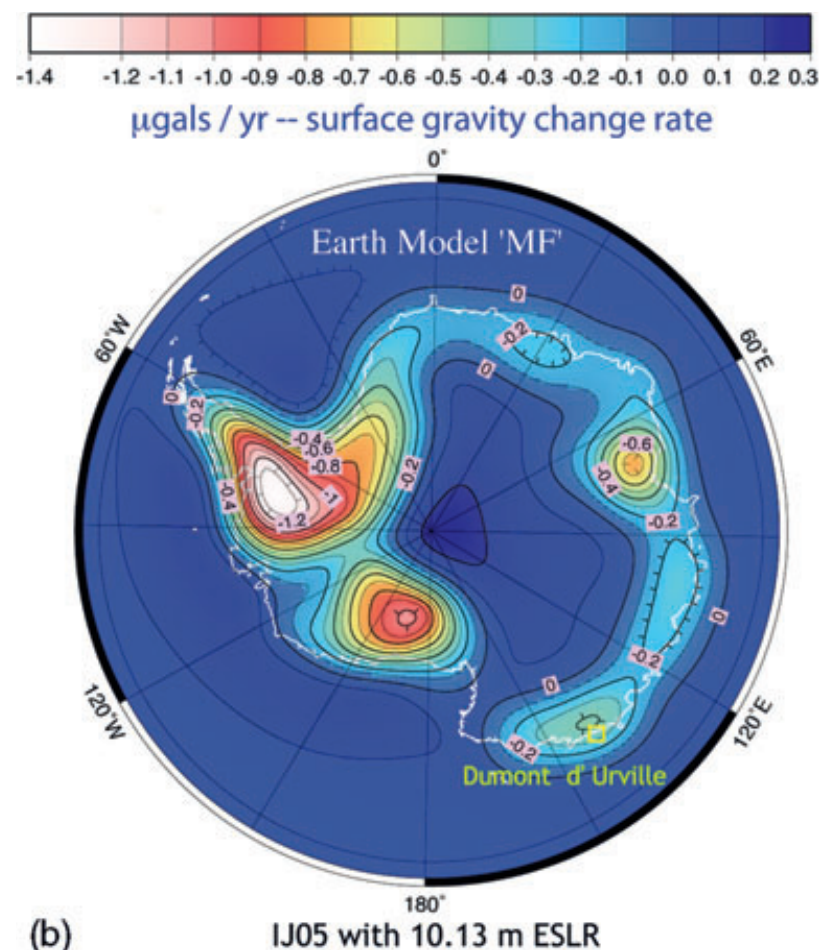

IJ05 with 10.13 m ESLR

Fig. 4 Prediction maps of (a) vertical displacement and (b) change of gravity from the IJ05 model.

and Table 1). The common time span extends from 1999 to 2005, providing almost 7 years of continuous observations. To validate these results with external comparison, we checked the horizontal velocities obtained at DdU from various geodetic or geophysical tectonic models. The values for the north and east components provided at http://sps.unavco.org/crustal_motion/dxdt/model are highly consistent with our results (Table 1), with $-12.05 \mathrm{~mm} \mathrm{yr}^{-1}$ and $8.15 \mathrm{~mm} \mathrm{yr}^{-1}$, respectively, from ITRF2000 (Altamimi et al. 2002), $-13.07 \mathrm{~mm} \mathrm{yr}^{-1}$ and $9.35 \mathrm{~mm} \mathrm{yr}^{-1}$, respectively, from REVEL 2000 (Sella et al. 2002), and $-11.64 \mathrm{~mm} \mathrm{yr}^{-1}$ and $7.47 \mathrm{~mm} \mathrm{yr}^{-1}$, respectively, from GSRM vl.2 (Kreemer et al. 2003). This agreement confirms the accuracy of our space geodetic results.

We analysed the DORIS and GPS time series to detect seasonal variations (Table 2). The GPS time series show annual signals of 1-2 $\mathrm{mm}$ in the horizontal components, and $5 \mathrm{~mm}$ in the vertical. No vertical annual signal is observed in the DORIS results. We are now attempting to link these variations with the seasonal ice mass fluctuations observed from recent satellite missions. Results from GRACE (Llubes et al. 2007), combined with Lageos data for the degrees 1 and 2 of the gravity field, and with data from ERS1 and ERS2 satellite altimetry (Wingham et al. 2006), showed seasonal variations over the whole continent. Although these two studies considered different
Table 2 Seasonal signatures of GPS and DORIS signals: periodicities and amplitudes.

\begin{tabular}{lll}
\hline & DORIS & GPS \\
\hline Vertical & 118 days & $1.023 \mathrm{yr}$ \\
North component & $5.68 \mathrm{~mm}$ & $5.04 \mathrm{~mm}$ \\
& $1.002 \mathrm{yr} / 118$ days & $1.013 \mathrm{yr}$ \\
East component & $12.17 \mathrm{~mm} / 8.67 \mathrm{~mm}$ & $1.32 \mathrm{~mm}$ \\
& 118 days & $3.333 \mathrm{yr} / 1.013 \mathrm{yr}$ \\
& $12.53 \mathrm{~mm}$ & $1.46 \mathrm{~mm} / 1.32 \mathrm{~mm}$ \\
\hline
\end{tabular}

time spans (1992-2003, Wingham et al. 2006; 20022005, Llubes et al. 2007), they agree globally with each other in assessing the seasonal elevation change over the whole continent. The ERS data (Wingham et al. 2006) reveal a global annual elevation change of $50 \mathrm{~mm}$, whereas the GRACE observations (Llubes et al. 2007) lead to seasonal variations of $15 \mathrm{~mm}$ water equivalent. Both studies claim to be representative of the whole continent, with coverage of 85 or $100 \%$, respectively, of the total area. These variations agree well with the in-phase annual signal we observe on the GPS vertical component (with the maximum loading effect observed in May or June). Nevertheless, a simple loading computation shows that the amplitude is too small to explain the GPS vertical signal. As the total area of the Antarctic Ice Sheet is $11.7 \times 10^{6} \mathrm{~km}^{2}$, we can roughly model it as a disc of 
Table 3 Vertical velocities and time gravity derivatives at Dumont d'Urville station, East Antarctica.

\begin{tabular}{lll}
\hline $\mathrm{d} u / \mathrm{dt}=$ & $0.34 \pm 0.12 \mathrm{~mm} \mathrm{yr}^{-1}$ & GPS measurements \\
$\mathrm{d} u^{\mathrm{v}} / \mathrm{d} t=$ & $2.49 \mathrm{~mm} \mathrm{yr}^{-1}$ & GIA modelling \\
$\mathrm{d} u^{\mathrm{e}} / \mathrm{d} t=$ & $-2.2 \mathrm{~mm} \mathrm{yr}^{-1}$ & $\mathrm{~d} u / \mathrm{d} t-\mathrm{d} u^{\mathrm{v}} / \mathrm{d} t$ \\
$\mathrm{~d}\left(\delta \mathrm{g}^{\mathrm{e}}\right) / \mathrm{d} t=$ & $0.59 \mathrm{~mm} \mathrm{yr}^{-1}$ & $\mathrm{~d} u^{\mathrm{e}} / \mathrm{d} t^{*} C^{\mathrm{ea}}$ \\
$\mathrm{d}\left(\delta \mathrm{g}^{\mathrm{v}}\right) / \mathrm{d} t=$ & $-0.37 \mathrm{~mm} \mathrm{yr}^{-1}$ & $\mathrm{~d} u^{\mathrm{v}} / \mathrm{d} t^{*} C^{\mathrm{vb}}$ \\
$\mathrm{d}(\delta \mathrm{g}) / \mathrm{dt}=$ & $0.22 \mathrm{~mm} \mathrm{yr}^{-1}$ & $\mathrm{~d}\left(\delta \mathrm{g}^{\mathrm{e}}\right) / \mathrm{d} t+\mathrm{d}\left(\delta \mathrm{g}^{\mathrm{v}}\right) / \mathrm{d} t$ \\
$\mathrm{~d}(\delta g) / \mathrm{d} t=$ & $-0.2 \pm 0.4 \mu \mathrm{Gal} \mathrm{yr} r^{-1}$ & $\mathrm{AG} \mathrm{measurements}$ \\
\hline${ }^{\mathrm{a}} C^{\mathrm{e}}$ is the conversion factor for elastic loading $\left(-0.27 \mu \mathrm{Gal} \mathrm{yr}^{-1}\right)$. \\
${ }^{\mathrm{b}} C^{\mathrm{v}}$ is the proportionality constant for viscous loading $\left(-0.15 \mu \mathrm{Gal} \mathrm{yr}^{-1}\right)$.
\end{tabular}

radius $1930 \mathrm{~km}$. A global ice thickness variation of $50 \mathrm{~mm}$ over this entire area will result in a $2.5-3 \mathrm{~mm}$ annual signal in DdU, whereas a change of $15 \mathrm{~mm}$ water equivalent over the same area will lead to $0.7-1 \mathrm{~mm}$ at most, far below the observed amplitude.

Our AG measurement results from DdU are in fair agreement with the GPS and DORIS vertical velocities, indicating little change in PDIM and quite small vertical displacement, resulting from the combined influence of GIA and elastic rebound.

As clearly reflected in the standard deviations, continuous geodetic observations from space provide more precise information about GIA effects than episodic AG measurements, which are more sensitive to one single measurement. Previous studies came to the same conclusion (Larson \& van Dam 2000; Lambert et al. 2006). A simple combined analysis of these data can be achieved if we assume that the AG data are free from local effects, such as snow-fall anomalies or unknown melt-freeze events in nearby subglacial lakes, and so on. This is the case of the DdU station, where no snowfall anomaly was observed during either of the two campaigns. The relationships developed by Wahr et al. (1995) apply if we further assume that all mass changes, including those of cryospheric origin, occur at a spherical surface, with radius $r=\tilde{a}$, below the AG position on the spherical surface, at $r=\tilde{a}+\Delta \tilde{a}$, with $\Delta \tilde{a} \geq 0$. These relationships provide a simple technique for distinguishing PDIM changes from GIA, and are quite analogous to the combination of geodetic data for ice mass and crustal motion in Svalbard discussed recently by Sato et al. (2006). We assume that the observed vertical displacement $\mathrm{d} u / \mathrm{d} t$ is the sum of the elastic PDIM term $\mathrm{d} u^{\mathrm{e}} / \mathrm{d} t$ and the viscous GIA term $\mathrm{d} u^{\mathrm{v}} / \mathrm{d} t$. Similarly, the total gravity change $\mathrm{d}(\delta g) / \mathrm{d} t$ is the result of PDIM-related variation $\mathrm{d}\left(\delta g^{\mathrm{e}}\right) / \mathrm{d} t$ and GIA effects $\mathrm{d}\left(\delta g^{\mathrm{v}}\right) / \mathrm{d} t$. The total $\mathrm{d} u / \mathrm{d} t$ displacement that we measured $\left(0.34 \pm 0.12 \mathrm{~mm} \mathrm{yr}^{-1}\right.$ from GPS and $0.29 \pm 0.13 \mathrm{~mm} \mathrm{yr}^{-1}$ from DORIS) is significantly different from the GIA uplift modelled in the IJ05 model (2.49 $\left.\mathrm{mm} \mathrm{yr}^{-1}\right)$, displayed in Table 3. If we accept the IJ05 prediction of the ground motion resulting from GIA as a reasonable a priori estimate, the stability we observe should result from two almost opposite vertical variations: $\mathrm{d} u^{\mathrm{v}} / \mathrm{d} t=2.49 \mathrm{~mm} \mathrm{yr}^{-1}$ and $\mathrm{d} u^{\mathrm{e}} / \mathrm{d} t=-2.2 \mathrm{~mm} \mathrm{yr}^{-1}$. We hypothesize that the contribution to the change in gravity caused by variability in PDIM, $\mathrm{d}\left(\delta g^{\mathrm{e}}\right) / \mathrm{d} t$, mainly results from the free-air gravity contribution $\mathrm{d} u^{\mathrm{e}} / \mathrm{d} t$ (a small redistribution of solid Earth mass and a small variation caused by the change in ice mass, as the site we measure is not situated on the ice). Providing the ice changes are widespread, and not concentrated at the AG site, the conversion factor for the ice elastic loading is about $-0.27 \mu \mathrm{Gal} \mathrm{mm}^{-1}$ (James \& Ivins 1998; Sato et al. 2006), leading to the conclusion that there is a positive ice elasticity induced gravity change $\mathrm{d}\left(\delta g^{\mathrm{e}}\right) / \mathrm{d} t$ of $+0.59 \mu \mathrm{Gal} \mathrm{yr}^{-1}$.

The viscous gravity change contribution $\mathrm{d}\left(\delta g^{v}\right) / \mathrm{d} t$, on the other hand, cannot be obtained in the same way, as GIA crustal motion is driven by a redistribution of mass within the Earth. The GIA term itself is the addition of $\mathrm{d}\left(\delta g_{\mathrm{m}}^{\mathrm{v}}\right)$, resulting from the change in the mass distribution of ice and solid Earth (referred to as the gravity anomaly), and of $\mathrm{d}\left(\delta g_{\mathrm{u}}^{\mathrm{v}}\right)$, resulting from the vertical displacement $\mathrm{d} u^{\mathrm{v}} / \mathrm{d} t$ (referred to as the free-air gravity contribution). We use the proportionality constant empirically determined by Wahr et al. (1995), for a wide range of viscosity profiles (see also James \& Ivins 1998), of $-0.15 \mu \mathrm{Gal} \mathrm{mm}{ }^{-1}$ to derive a value of $-0.37 \mu \mathrm{Gal} \mathrm{yr}^{-1}$ for $\mathrm{d}\left(\delta g^{\mathrm{v}}\right) / \mathrm{d} t$ from the modelled value of $\mathrm{d} u^{\mathrm{v}} / \mathrm{d} t$.

The present-day value of $\mathrm{d}(\delta g) / \mathrm{d} t$ is therefore the sum of the viscous and elastic terms: $-0.37+0.59=$ $+0.22 \mu \mathrm{Gal} \mathrm{yr}^{-1}$. Note that this stability in gravity is fully compatible with the lack of significant change observed over 6 years of AG measurements in DdU (-0.2 \pm

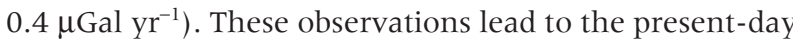
stability of this part of the EAIS. Wingham et al. (2006), using ERS-1 and ERS-2 data to determine the rate of elevation change of individual ice drainage basins, came to the same conclusion. They obtained a $5 \pm 2 \mathrm{~mm} \mathrm{yr}^{-1}$ elevation rate in the $0.74 \times 10^{6} \mathrm{~km}^{2}$ basin enclosing DdU. This corresponds to a vertical ground motion $\mathrm{d} u / \mathrm{d} t$ of $0.08 \mathrm{~mm} \mathrm{yr}^{-1}$. If we now consider a wider area, as far as $1000 \mathrm{~km}$ away from DdU, which corresponds to the DdU and the surrounding basins, we obtain a mean ice elevation change of $0.8 \mathrm{~mm} \mathrm{yr}^{-1}$ over a $3.1 \times 10^{6} \mathrm{~km}^{2}$ area. The resulting vertical motion is less than $0.02 \mathrm{~mm} \mathrm{yr}^{-1}$. Our conclusions are also in accord with the recent results derived by Rignot et al. (2008) for the region, wherein the total accumulation was nearly balanced by the ice outflux (with a slight gain of $1 \pm 19$ gigatonnes per yr) averaged over $3.3 \times 10^{7} \mathrm{~km}^{2}$ in the drainage system upstream from DdU during 1996-2006. This gain corresponds to a regional average ice elevation change of about $+0.04 \pm 0.65 \mathrm{~mm} \mathrm{yr}^{-1}$. 
Finally, we investigated the circum-Antarctic sea level variability to look for some consistency with these conclusions concerning ice mass stability, or the slight gain over the period of observation. Unfortunately, no conclusion can be drawn from the pressure tide gauge that was installed in DdU in 1997, because of gaps in the time series. Other Southern Ocean instruments indicate coherent rates of sea level rise: Testut et al. (2006) observed $1.1 \pm 0.7 \mathrm{~mm} \mathrm{yr}^{-1}$ at the Kerguelen Islands; Hunter et al. (2003) measured $0.8 \pm 0.2 \mathrm{~mm} \mathrm{yr}^{-1}$ at Port Arthur (Tasmania); and Woodworth et al. (2005) reported $0.7 \pm 0.25 \mathrm{~mm} \mathrm{yr}^{-1}$ at Port Stanley (Falkland Islands). These rates are likely to result from the combined global volume increase, and from the inherent dynamic nature of the Antarctic Circumpolar Current (White et al. 1998), and are probably unrelated to direct gravitational effects of ice mass variability or to GIA.

This study assessed the isostatic stability of the EAIS area surrounding DdU. To draw wider conclusions about the behaviour of the EAIS, these results should be compared with other East Antarctic station GNSS vertical velocity and absolute gravity measurements. Unfortunately, the density of human bases on this part of East Antarctica remains poor. The nearest station (Casey, Australia) is more than $1300 \mathrm{~km}$ away, and is only equipped with a GPS antenna. The Japanese Syowa station employs a combination of techniques: GPS, DORIS, VLBI, AG and superconducting gravimeter (SG) measurements (Fukuzaki et al. 2005; Ohzono et al. 2006), but implementation of the AG data remains a work in progress. The focus of our results is limited to the DdU area (up to $1000 \mathrm{~km}$ inland and along the coast).

\section{Conclusion}

The combination of vertical data from independent geodetic techniques-DORIS and GPS - and absolute gravity in DdU, Antarctica, shows very good agreement between the three data sets, pointing to a consistency and resolution within each technique equivalent to ca. $0.5 \mathrm{~mm} \mathrm{yr}^{-1}$ or better. From our comparison of the measurements from both AG and vertical displacements (GPS and DORIS) with GIA models in DdU, we conclude that this part of EAIS is stable, or that it is possibly experiencing a small increase in ice mass. The observed vertical displacement is $0.3 \pm 0.13 \mathrm{~mm} \mathrm{yr}^{-1}$, which, using the predicted value for the GIA contribution, leads to an elastic contribution of $-2.2 \mathrm{~mm} \mathrm{yr}^{-1}$. This is not inconsistent with recent studies, employing the GRACE, altimetry and flux methods, regarding the near balanced state of the present-day EAIS (Rignot \& Thomas 2002; Davis et al. 2005; Ramilien et al. 2006; Remy \& Frezzotti 2006; Velicogna \& Wahr 2006; Wingham et al. 2006; Rignot et al. 2008). We conclude that permanent GNSS instruments provide precise information about the GIA and PDIM effects. Conjoining the displacement measurements with GIA modelling, we can estimate a predicted small AG variation in $\mathrm{DdU}$ ca. $+0.22 \mu \mathrm{Gal} \mathrm{yr}^{-1}$. This is statistically indistinguishable from our weakly constrained observation over a period of 6 years, showing a

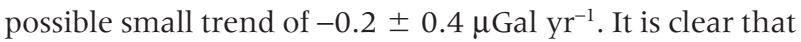
this constraint should improve in the future when more AG measurements become available.

\section{Acknowledgements}

Part of this research was carried out at the Jet Propulsion Laboratory, California Institute of Technology, under a contract with NASA, and support for ERI was provided by the Earth Surface and Interior Focus Area of NASA's Earth Science Directorate. The financial and logistical support of the Institut Paul-Emile Victor made possible the installation and maintenance of the GPS station DUMl, as well as the data transfer and the AG measurement campaigns. The authors are indebted to the Terres Australes et Antarctiques Françaises for their logistical support. This paper is Institut de Physique du Globe de Paris (IPGP) contribution number 2329.

\section{References}

Altamimi Z., Collilieux X., Legrand J., Garayt B. \& Boucher C. 2007. ITRF2005: a new release of the International Terrestrial Reference Frame based on time series of station positions and Earth Orientation Parameters. Journal of Geophysical Research—Solid Earth 112, B09401, doi: 10.1029/ 2007JB004949.

Altamimi Z., Sillard P. \& Boucher C. 2002. ITRF2000: a new release of the International Terrestrial Reference Frame for Earth science applications. Journal of Geophysical Research-Solid Earth 107, 2214, doi: 10.1029/ 2001JB000561.

Amalvict M., Hinderer J. \& Luck B. 2001. First absolute gravity measurements at the French station Dumont d'Urville (Antarctica). In M. Sideris (ed.): Gravity, geoid and geodynamics 2000. GGG2000 IAG International Symposium, Banf, Alberta, Canada, July 31-August 4, 2000. Pp. 373-377. Heidelberg: Springer.

Amalvict M., Rogister Y., Hinderer J., Luck B., McQueen H. \& Luton G. 2007. Absolute gravity measurements in Terre Adélie (Antarctica) and at Canberra (Australia). Gravity field of the Earth. Proceedings of the First International Symposium of the International Gravity Field Service. Harita Dergisi Special Issue 18, 409-413.

Blewitt G. \& Lavallée D. 2002. Effect of annual signals on geodetic velocity. Journal of Geophysical Research-Solid Earth 107, 2156, doi: 10.1029/2001JB000570. 
Boehm J., Niell A., Tregoning P. \& Schuh H. 2006. Global mapping function (GMF): a new empirical mapping function based on numerical weather model data. Geophysical Research Letters 33, L07304, doi: 10.1029/ 2005 GL025546.

Boehm J., Werl B. \& Schuh H. 2006. Troposphere mapping functions for GPS and very long baseline interferometry from European Centre for Medium-Range Weather Forecasts operational analysis data. Journal of Geophysical Research-Solid Earth 111, B02406, doi: 10.1029/ 2005JB003629.

Bouin M.N. \& Vigny C. 2000. New constraints on Antarctic plate motion and deformation from GPS data. Journal of Geophysical Research-Solid Earth 105, 28279-2893.

Chen J.L., Wilson C.R., Blankenship D.D. \& Tapley B.D. 2006. Antarctic mass change rates from GRACE. Geophysical Research Letters 33, L11502, doi: 10.1029/ 2006GL026369.

Davis C.H., Li Y.H., McConnel J.R., Frey M.M. \& Hanna E. 2005. Snowfall-driven growth in east Antarctic ice sheet mitigates recent sea-level rise, Science 308, 1898-1901.

Domack E.W., Jull A.T. \& Nakao S. 1991. Advance of East Antarctic outlet glaciers during the Hypsithermal: implications for the volume state of the Antarctic ice sheet under global warming. Geology 19, 1059-1062.

Dow J.M., Neilan R.E. \& Gendt G. 2005. The International GPS Service: celebrating the 10th anniversary and looking to the next decade. Advances in Space Research 36, 320-326.

Fagard H. 2006. Twenty years of evolution for the DORIS permanent network: from its initial deployment to its renovation. Journal of Geodesy 80, 429-456.

Feissel-Vernier M., de Viron O. \& Le Bail K. 2007. Stability of VLBI, SLR, DORIS and GPS positioning. Earth Planets and Space 59, 475-497.

Fukuzaki Y., Shibuya K., Doi K., Ozawa T., Nothnagel A., Jike T., Iwano S., Jauncey D.L., Nicolson G.D. \& McCulloch P.M. 2005. Results of the VLBI experiments conducted with Syowa Station, Antarctica. Journal of Geodesy 79, 379-388.

Hinderer J., Amalvict M. \& Luck B. 2002. Premières mesures françaises de gravimétrie absolue dans les régions polaires Antarctique (Terre Adélie) et Arctique (Spitzberg). (First French measurements of absolute gravity in the Antarctic [Terre Adélie] and Arctic [Spitsbergen] polar regions.) Comptes Rendus Geoscience 334, 819-826.

Hunter J., Coleman R. \& Pugh D. 2003. The sea level at Port Arthur, Tasmania, from 1841 to the present. Geophysical Research Letters 30, 1401.

Ivins E.R. \& James T.S. 2005. Antarctic glacial isostatic adjustment: a new assessment. Antarctic Science 17, $541-553$.

James T.S. \& Ivins E.R. 1998. Predictions of Antarctic crustal motions driven by present-day ice sheet evolution and by isostatic memory of the Last Glacial Maximum. Journal of Geophysical Research—Solid Earth 103, 4993-5017.
King R.W. \& Bock Y. 2005. Documentation for the GAMIT GPS analysis software. Release 10.2. Cambridge, MA:

Massachusetts Institute of Technology.

Kreemer C., Holt W.E. \& Haines A.J. 2003. An integrated global model of present-day plate motions and plate boundary deformation. Geophysical Journal International 154, 8-34.

Lambert A., Courtier N. \& James T.S. 2006. Long-term monitoring by absolute gravimetry: tides to post-glacial rebound. Journal of Geodynamics 41, 307-317.

Larson K.M. \& van Dam T. 2000. Measuring postglacial rebound with GPS and absolute gravity. Geophysical Research Letters 27, 3925-3928.

Llubes M., Lemoine J.M. \& Rémy F. 2007. Antarctica seasonal mass variations detected by GRACE. Earth and Planetary Science Letters 260, 127-136.

Mäkinen J., Amalvict M., Shibuya K. \& Fukuda Y. 2007. Absolute gravimetry in Antarctica: status and prospects. Journal of Geodynamics 43, 339-357.

Mitrovica J.X. \& Forte A.M. 2004. A new inference of mantle viscosity based upon joint inversion of convection and glacial isostatic adjustment data. Earth and Planetary Science Letters 225, 177-189.

Nerem R.S., Leuliette E. \& Cazenave A. 2006. Present-day sea-level change: a review. Comptes Rendus Geoscience 338, 1077-1083.

Ohzono M., Tabei T., Doi K., Shibuya K. \& Sagiya T. 2006. Earth, Planets and Space 58, 795-804.

Ramilien G., Lombard A., Cazenave A., Ivins E.R., Llubes M., Remy F. \& Biancale R. 2006. Interannual variations of the mass balance of the Antarctica and Greenland ice sheets from GRACE. Global and Planetary Change 53, 198-208.

Remy F. \& Frezzotti M. 2006. Antarctica ice sheet mass balance. Comptes Rendus Geoscience 338, 1084-1097.

Rignot E., Bamber J.L., van den Broeke M.R., Davis C., Li Y., van de Berg W.J. \& van Meijgaard E. 2008. Recent Antarctic ice mass loss from radar interferometry and regional climate modeling. Nature Geoscience 1, 106-110.

Rignot E. \& Thomas R.H. 2002. Mass balance of polar ice sheets. Science 297, 1502.

Sato T., Okuno J., Hinderer J., MacMillan D.S., Plag H.-P., Francis O., Falk R. \& Fukuda Y. 2006. A geophysical interpretation of the secular displacement and gravity rates observed at Ny-Ålesund, Svalbard in the Arctic: effects of the post-glacial rebound and present-day ice melting, Geophysical Journal International 165, 729-743.

Sella G.F., Dixon T.H. \& Mao A. 2002. REVEL: a model for recent plate velocities from space geodesy. Journal of Geophysical Research—Solid Earth 107, 2081, doi: 10.1029/ 2000JB000033.

Snajdrova K, Boehm J, Willis P., Haas R. \& Schuh H. 2006. Multi-technique comparison of tropospheric zenith delays derived during the CONT02 campaign. Journal of Geodesy $79,613-623$.

Tavernier G., Fagard H., Feissel-Vernier M., Le Bail K., Lemoine F., Noll C., Noomen R., Ries J.C., Soudarin L., 
Valette J.J. \& Willis P. 2006. The International DORIS Service: fenesis and early achievements. Journal of Geodesy 80, 403-417.

Testut L., Wöppelmann G., Simon B. \& Téchiné P. 2006. The sea level at Port-aux-Français, Kerguelen Island, from 1950 to the present. Ocean Dynamics 56, 464-472.

Toracinta R.E., Oglesby R.J. \& Bromwich D.H. 2004. Atmospheric response to modified CLIMAP ocean boundary conditions during the Last Glacial Maximum. Journal of Climate 17, 504-522.

Tregoning, P., van Dam, T., 2005. Atmospheric pressure loading corrections applied to GPS data at the observation level. Geophysical Research Letters 32, L22310, doi: 10.1029/ 2005 GL024104.

Velicogna I. \& Wahr J. 2006. Measurements of time-variable gravity show mass loss in Antarctica. Science 311, 1754-1756.

Wahr J., Han D. \& Trupin A. 1995. Predictions of vertical uplift caused by changing polar ice volumes on a viscoelastic Earth. Geophysical Research Letters 22, 977-980.

White W.B., Chen S.C. \& Peterson R.G. 1998. The Antarctic circumpolar wave: a beta effect in ocean-atmosphere coupling over the Southern Ocean. Journal of Physical Oceanography 28, 2345-2361.

Willis P., Bar-Sever Y.E. \& Tavernier G. 2005. DORIS as potential part of a global geodetic observing system.Journal of Geodynamics 40, 494-501.

Willis P., Berthias J.P. \& Bar-Sever Y.E. 2006. Systematic errors in Z-geocenter derived from sun-synchronous satellite data: a case study from SPOT4/DORIS 1998 data. Journal of Geodesy 79, 567-572.

Willis P. \& Ries J.C. 2005. Defining a DORIS core network for Jason-1 precise orbit determination based on
ITRF2000: method and realization. Journal of Geodesy 79, 370-378.

Wingham D.J., Sheperd A., Muir A. \& Marshall G.J. 2006. Mass balance of the Antarctic ice sheet. Philosophical Transactions of the Royal Society A 364, 1627-1635.

Wolff E.W., Fischer H., Fundel F., Ruth U., Twarloh B., Littot G.C., Mulvaney R., Rothlisberger R., de Angelis M., Boutron C.F., Hansson M., Jonsell U., Hutterli M.A., Lambert F., Kaufmann P., Stauffer B., Stocker T.F., Steffensen J.P., Bigler M., Siggaard-Andersen M.L., Udisti R., Becagli S., Castellano E., Severi M., Wagenbach D., Barbante C., Gabrielli P. \& Gaspari V. 2006. Southern Ocean sea-ice extent, productivity and iron flux over the past eight glacial cycles. Nature 440, 491496.

Woodworth P.L., Pugh D.T., Meredith M.P. \& Blackman D.L. 2005. Sea level changes at Port Stanley, Falkland Islands. Journal of Geophysical Research-Oceans 110, C06013, doi: 10.1029/2004JC002648.

Wöppelmann G., Bouin M.N. \& Altamimi Z. 2008. Terrestrial reference frame implementation in global GPS analysis at TIGA ULR consortium. Physics and Chemistry of the Earth 33, 217-224.

Wöppelmann G., Martin Miguez B., Bouin M.N. \& Altamimi Z. 2007. Geocentric sea-level trend estimates from GPS analyses at relevant tide gauges world-wide. Global and Planetary Change 57, 396-406.

Zwally H.J., Giovinetto M.B., Li J., Cornejo H.G., Beckley M.A., Brenner A.C., Saba J.L. \& Yi D. 2005. Mass changes of the Greenland and Antarctic ice sheets and shelves and contributions to sea-level rise: 1992-2002. Journal of Glaciology 51, 509-527. 